\title{
Bio-based PBS copolyesters derived from a bicyclic D-glucitol
}

\author{
Elena Zakharova, Abdelilah Alla, \\ Antxon Martínez de Ilarduya and Sebastián Muñoz-Guerra \\ Departament d'Enginyeria Química, Universitat Politècnica de Catalunya, \\ ETSEIB, Diagonal 647, 08028 Barcelona, Spain \\ Corresponding author: sebastian.munoz@upc.edu
}

2,4:3,5-di-O-methylene-D-glucitol (Glux-diol) was used for the synthesis of poly(butylene succinate) (PBS) copolyesters by melt polycondensation. Glux-diol possess a rigid bicyclic asymmetric structure made of two fused 1,3-dioxane rings and two hydroxyl functions at the end positions. Copolyesters were prepared over the whole range of compositions with molecular weights varying from 26,000 to $46,000 \mathrm{~g} \cdot \mathrm{mol}^{-1}$ and a random microstructure. The thermal stability of PBS did not significantly alter with the presence of Glux units. The glass transition temperatures $\left(T_{\mathrm{g}}\right)$ steadily increased from -28 to $80^{\circ} \mathrm{C}$ along the whole copolyester series with the insertion of Glux. On the contrary, melting temperature $\left(T_{\mathrm{m}}\right)$ and crystallinity decreased because of lack of regularity of the polymer chain although copolyesters with contents of Glux units up to 30 mole- $\%$ were semicrystalline. The stress-strain behavior changed according to variations produced in thermal transitions. The replacement of 1,4-butanediol by Glux-diol slightly increased both the hydrolytic degradability and the biodegradability of PBS. Compared to other bicyclic sugar-based diols reported in the literature, Glux-diol appeared to be more efficient in both increasing the $T_{\mathrm{g}}$ and enhancing the susceptibility to hydrolysis of PBS.

\section{Introduction}

A growing interest for chemicals derived from renewable resources which are able to replace oil-based monomers for the production of industrial polymers is noticeable in these last years. ${ }^{1,2}$ Additionally, environmental pollution has recently become a big problem of both social and technical repercussions due largely to the high impact of plastic wastes. ${ }^{3}$ The most popular approach followed today to give response to these concerns is to replace the commodity synthetic polymers by biobased polymers. ${ }^{4,5,6}$ In fact, polymers made from monomers derived from non-fossil materials are sustainable and also total or partially susceptible to microbial degradation. ${ }^{7}$ Aliphatic polyesters such as poly(L-lactic acid), poly(butylene succinate), and polyhydroxyalkanoates among others, constitute primary examples of bio-based 
polymers that distinguish by being fully renewable and displaying partial or total biodegradability. Such features make aliphatic polyesters especially suitable for largetonnage applications where large consumption of raw materials and high environmental impact are major concerns, e.g. packaging, disposable items and agricultural mulch films. ${ }^{8}$

Poly(butylene succinate) (PBS) is one of the members of the aliphatic polyester family that is receiving greatest attention. This polyester not only may be built by using exclusively renewable feedstock but it also displays mechanical properties comparable to other extensively used conventional polymers. ${ }^{9}$ Furthermore, PBS has been demonstrated to exhibit significant biodegradation in soil, activated sludge and sea water. ${ }^{10}$ Due to its outstanding potential, PBS is today in the focus of an intensive research addressed to improve its thermal and mechanical properties without significant detriment to its sustainability and biodegradability. Copolymerization involving cyclic comonomers and blending with nanofillers are the main approaches followed in this regard. ${ }^{11,12}$

Carbohydrates stand out as very convenient raw materials for furnishing polycondensation monomers. They are relatively inexpensive, readily available, and provide broad functional diversity. In recent years, a large number of examples of polycondensation polymers made from carbohydrate derivatives have been reported in the literature. ${ }^{13,14}$ Cyclic carbohydrate-based monomers are particularly relevant because their stiff structures are able to increase the glass transition temperature and hence to improve certain polymer properties such as heat deflection temperature, hardness, tearing resistance and permeability. Isohexides and more specifically isosorbide, are bicyclic dianhydride diols coming from hexoses that have been widely investigated for their potential to enhance the performance of both aliphatic and aromatic polyesters. ${ }^{15,16}$ More recently, carbohydrate-based bicyclic diols and diacids with a diacetal constitution have emerged as a new class of bio-based monomers with a potential at least comparable to that of isohexides. ${ }^{17,18}$ Most exciting results have 
been those attained with aromatic copolyesters containing fused diacetalized bicyclic units derived from D-mannose and D-glucose..$^{19,20}$ These novel sugar-based copolyesters have been reported to exhibit enhanced thermal properties and biodegradability when compared to PET and PBT. ${ }^{19 b, 20 b}$

The purpose of this work is to explore the effects on properties of PBS caused by the presence of carbohydrate-based diacetalized bicyclic units in the polymer chain, more specifically of 2,4:3,5-di-O-methylene-D-glucitol, abbreviated as Glux-diol. We have very recently reported on PBS copolyesters made from Manx-diol, the stereoisomer of Glux-diol that derives from D-mannose. ${ }^{21}$ Both isomers consist of two fused 1,3-dioxane rings structure sharing a C6-segment backbone that bears two hydroxyl functions at the end positions. At difference with Manx-diol, Glux-diol is asymmetric so its two $\mathrm{OH}$ groups are spatially and hence chemically different (Scheme 1). Random PBS copolyesters containing Manx units could be obtained with $M_{\mathrm{w}}$ above 30,000 , they were semicrystalline for the whole range of compositions and displayed enhanced $T_{\mathrm{g}}$ and biodegradability. Since polymerization rate as well as polymer properties are largely depending on monomer symmetry, it is of much conceptual interest to compare Manx and Glux diols as comonomers for the production of PBS copolyesters. Additionally, data obtained from this study can be related to those reported for PBS copolyesters containing isosorbide in order to assess diacetalized and dianhydride bicyclic diols as optional comonomers for their capacity to improve PBS properties. The study is also of practical relevance since Glux-diol is a compound coming from D-glucose, the most available monosaccharide in nature.

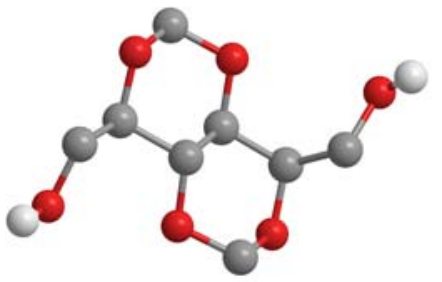

a)

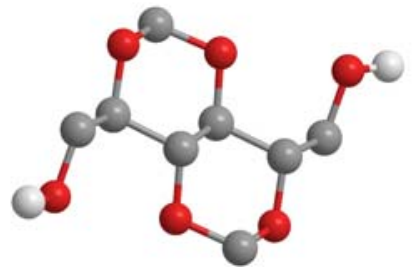

b)

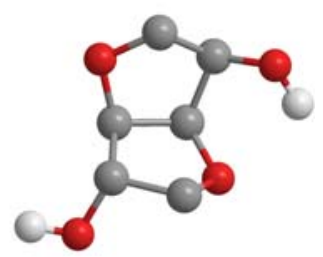

c)

Scheme 1 Molecular structures of Manx-diol (a), Glux-diol (b) and isosorbide (c). 


\section{Experimental part}

\section{Materials}

The reagents 1,4-butanediol (BD) (97\%), dimethyl succinate (DMS) (> 99\%), 1,5-D-gluconolactone (99\%), lithium aluminium hydride (95\%), paraformaldehyde $(>95 \%)$, sodium hydroxide ( $>97 \%)$ and the catalyst dibutyl tin oxide (DBTO, $98 \%$ ), were purchased from Sigma-Aldrich. Lipase from porcine pancreas (activity 15-35 U, $3 \mathrm{mg}^{-1}$, $\mathrm{pH} 8.0,37^{\circ} \mathrm{C}$ ) was also purchased from Sigma-Aldrich. Solvents used for purification, synthesis and characterization were all of either technical or high-purity grade and they were purchased from Panreac and used as received without further purification. Irganox 1010, Irgafos 126 antioxidants were a generous gift from BASF. The cyclic diol 2,4:3,5-di-O-methylene-D-glucitol (Glux-diol) has been prepared following a procedure well described in the recent literature. ${ }^{22}$

\section{General methods}

${ }^{1} \mathrm{H}$ and ${ }^{13} \mathrm{C}$ NMR spectra were recorded on a Bruker AMX-300 spectrometer at $25.0{ }^{\circ} \mathrm{C}$ operating at 300.1 and $75.5 \mathrm{MHz}$, respectively. Polyesters were dissolved either in deuterated chloroform or in a mixture of deuterated chloroform/ trifluoroacetic acid (TFA) (1/1), and spectra were internally referenced to tetramethylsilane (TMS). About 10 and $50 \mathrm{mg}$ of sample dissolved in $1 \mathrm{~mL}$ of solvent were used for ${ }^{1} \mathrm{H}$ and ${ }^{13} \mathrm{C}$ NMR, respectively. Sixty-four scans were acquired for ${ }^{1} \mathrm{H}$ and $1,000-10,000$ for ${ }^{13} \mathrm{C}$ with 32 and $64-\mathrm{K}$ data points as well as relaxation delays of 1 and $2 \mathrm{~s}$, respectively. Viscosities of polyesters were measured in dichloroacetic acid at $25.00 \pm 0.01{ }^{\circ} \mathrm{C}$, using a capillary viscosimeter at concentrations ranging from 5 to $10 \mathrm{mg} \cdot \mathrm{mL}^{-1}$. Gel permeation chromatograms were acquired at $35.0{ }^{\circ} \mathrm{C}$ with a Waters equipment provided with a refraction-index detector. The samples were chromatographed with $0.05 \mathrm{M}$ sodium trifluoroacetate-hexafluoroisopropanol (NaTFA-HFIP) using a PL HFIPgel $300 \times 7.5 \mathrm{~mm}$ column with a flow rate of $0.5 \mathrm{~mL} \cdot \mathrm{min}^{-1}$. Chromatograms were calibrated against poly(methyl methacrylate) (PMMA) monodisperse standards. The 
116 thermal behavior of polyesters was examined by DSC using a Perkin Elmer DSC Pyris

117 1. DSC data were obtained from 3 to $5 \mathrm{mg}$ samples at heating/cooling rates of 10

$118{ }^{\circ} \mathrm{C} \cdot \mathrm{min}^{-1}$ under a nitrogen flow of $20 \mathrm{~mL} \cdot \mathrm{min}^{-1}$. Indium and zinc were used as standards

119 for temperature and enthalpy calibration. The glass-transition temperatures were determined by the tangent method at a heating rate of $20^{\circ} \mathrm{C} \cdot \mathrm{min}^{-1}$ from rapidly meltquenched polymer samples. The treatment of samples for isothermal crystallization experiments was the following: the thermal history was removed by heating the sample up to $200^{\circ} \mathrm{C}$ and left at this temperature for $5 \mathrm{~min}$, and then it was cooled at $20^{\circ} \mathrm{C} \cdot \mathrm{min}^{-}$ 1 to the selected crystallization temperature, where it was left to crystallize until saturation. Thermogravimetric analyses were performed under a nitrogen flow of 20 $\mathrm{mL} \cdot \mathrm{min}^{-1}$ at heating rate of $10^{\circ} \mathrm{C} \cdot \mathrm{min}^{-1}$, within a temperature range of 30 to $600{ }^{\circ} \mathrm{C}$, using a Mettler Toledo TGA/DSC 1 thermobalance. Sample weights of about $10-15 \mathrm{mg}$ were used in these experiments. Films for mechanical properties with a thickness of $\sim 200 \mu \mathrm{m}$ were prepared by the hot-pressing method. The tested samples were cut into strips with a width of $3 \mathrm{~mm}$ while the distance between testing marks was $10 \mathrm{~mm}$. The tensile strength, elongation at break and Young's modulus were measured at a stretching rate of $30 \mathrm{~mm} \cdot \mathrm{min}^{-1}$ on a Zwick 2.5/TN1S testing machine coupled with a compressor Dalbe DR 150. Each sample was measured five times. X-ray diffraction patterns were recorded on the PANalytical X'Pert PRO MPD $\theta / \theta$ diffractometer using the $\mathrm{Cu} \mathrm{Ka}$ radiation of wavelength $0.1542 \mathrm{~nm}$ from powdered samples coming from synthesis.

Polymer synthesis

Copolyesters of PBS containing Glux units $\left(\mathrm{PB}_{\mathrm{x}} \mathrm{Glux} \mathrm{y}\right.$ s with subscripts $\mathrm{x}$ and $\mathrm{y}$ standing for mole- $\%$ of BD and Glux units in the feed respectively) were synthesized by reaction of dimethyl succinate with mixtures of 1,4-butanediol and 2,4:3,5-di-Omethylene-D-glucitol at different selected ratios. PBS and PGluxS homopolyesters were obtained by polycondensation of dimethyl succinate with 1,4-butanediol and 
2,4:3,5-di-O-methylene-D-glucitol, respectively. Since diols were partially streamed off

144

145

146

147 by the nitrogen flow and also volatilized when the high vacuum was applied, a mole$10 \%$ excess of the diols respect to the diester monomer was used in all cases. The antioxidants Irganox $1010(0.2 \% \mathrm{w} / \mathrm{w})$ and Irgafos $126(0.6 \% \mathrm{w} / \mathrm{w})$ were added to minimize degradation of thermally sensitive sugar-based monomers. The same reaction protocol was applied for all compositions. Reactions were carried out in a three-necked, cylindrical bottom flask equipped with a mechanical stirrer, a nitrogen inlet and a vacuum distillation outlet. The reactants were stirred to get a homogeneous mixture and DBTO (0.4-0.6 mole-\% respect to the total of monomers) was added as catalyst. The transesterification step was performed for $3-5 \mathrm{~h}$ at $160{ }^{\circ} \mathrm{C}$ under nitrogen flow, and polycondensation for 7-8 $\mathrm{h}$ at $160-180{ }^{\circ} \mathrm{C}$ under vacuum (0.03-0.06 mbar). The final reaction mixture was cooled to room temperature under a nitrogen flow to prevent degradation, the resulting solid mass was dissolved in chloroform, and the polymer precipitated with methanol, collected by filtration and dried under vacuum. The NMR data ascertaining their constitution and purity are described below.

PBS homopolyester: ${ }^{1} \mathrm{H}$ NMR (300.1 MHz, $\left.\mathrm{CDCl}_{3}\right), \delta(\mathrm{ppm}): 4.1\left(\mathrm{t}, 4 \mathrm{H}, \mathrm{OCH}_{2} \mathrm{CH}_{2} \mathrm{CH}_{2}\right.$ ), $2.6\left(\mathrm{~s}, \quad 4 \mathrm{H}, \quad \mathrm{COCH}_{2} \mathrm{CH}_{2} \mathrm{CO}\right), 1.7$ (t, $\left.4 \mathrm{H}, \quad \mathrm{OCH}_{2} \mathrm{CH}_{2} \mathrm{CH}_{2}\right) .{ }^{13} \mathrm{C} \quad \mathrm{NMR}(75.5 \mathrm{MHz}$, $\left.\mathrm{CDCl}_{3} / \mathrm{TFA}\right), \delta(\mathrm{ppm}): 176.7$ (CO), 65.1, 29.0, 25.2.

$P B_{x}$ Glux ${ }_{y}$ S copolyesters: ${ }^{1} \mathrm{H}$ NMR (300.1 MHz, $\left.\mathrm{CDCl}_{3}\right), \delta(\mathrm{ppm}): 5.2-4.8(\mathrm{~m}, \mathrm{y} \cdot 4 \mathrm{H}$, $\left.\mathrm{OCH}_{2} \mathrm{O}\right), 4.6-4.4\left(\mathrm{~m}, \mathrm{y} \cdot 2 \mathrm{H}, \mathrm{OCH}_{2} \mathrm{CH}\right), 4.4-4.2\left(\mathrm{~m}, \mathrm{y} \cdot 4 \mathrm{H}, \mathrm{OCH}_{2} \mathrm{CH}\right), 4.2-4.1(\mathrm{~m}, \mathrm{y} \cdot 1 \mathrm{H}$, $\left.\mathrm{OCH}_{2} \mathrm{CHCH}\right), 4.2-4.0\left(\mathrm{t}, \mathrm{x} \cdot 4 \mathrm{H}, \mathrm{COCH}_{2} \mathrm{CH}_{2}\right), 3.9\left(\mathrm{~m}, \mathrm{y} \cdot 1 \mathrm{H}, \mathrm{OCH}_{2} \mathrm{CHCH}\right), 3.8-3.7$ (t, $\left.\mathrm{y} \cdot 1 \mathrm{H}, \quad \mathrm{OCH}_{2} \mathrm{CHCH}\right), \quad 3.7-3.6 \quad\left(\mathrm{t}, \quad \mathrm{y} \cdot 1 \mathrm{H}, \quad \mathrm{OCH}_{2} \mathrm{CHCHCHCH}\right), \quad 2.7-2.6 \quad(\mathrm{t}, \quad \mathrm{x} \cdot 4 \mathrm{H}$, $\mathrm{COCH}_{2} \mathrm{CH}_{2} \mathrm{CO}$ ), 2.7-2.6 (t, y.4H, $\mathrm{COCH}_{2} \mathrm{CH}_{2} \mathrm{CO}$ ), 1,7 (t, $\left.\mathrm{x} \cdot 4 \mathrm{H} \mathrm{OCH}_{2} \mathrm{CH}_{2} \mathrm{CH}_{2}\right){ }^{13} \mathrm{C}^{\mathrm{N} M R}$ (75.5 MHz, $\left.\mathrm{CDCl}_{3} / \mathrm{TFA}\right), \delta$ (ppm):176.7 (CO), 93.2, 88.3, 76.2, 74.5, 71.5, 68.4, 67.0, $65.1,61.8,29,0,25.2$.

PGluxS homopolyester: ${ }^{1} \mathrm{H}$ NMR $\left(300.1 \mathrm{MHz}, \mathrm{CDCl}_{3}\right), \delta(\mathrm{ppm}): 5.2-4.8(\mathrm{~m}, 4 \mathrm{H}$, $\left.\mathrm{OCH}_{2} \mathrm{O}\right), 4.6-4.4\left(\mathrm{~m}, 2 \mathrm{H}, \mathrm{OCH}_{2} \mathrm{CH}\right), 4.4-4.2\left(\mathrm{~m}, 4 \mathrm{H}, \mathrm{OCH}_{2} \mathrm{CH}\right), 4.2-4.1(\mathrm{~m}, 1 \mathrm{H}$, $\left.\mathrm{OCH}_{2} \mathrm{CHCH}\right), 3.9\left(\mathrm{~m}, 1 \mathrm{H}, \mathrm{OCH}_{2} \mathrm{CHCH}\right), 3.8-3.7\left(\mathrm{t}, 1 \mathrm{H}, \mathrm{OCH}_{2} \mathrm{CHCH}\right), 3.7-3.6(\mathrm{t}, 1 \mathrm{H}$, 
$\mathrm{OCH}_{2} \mathrm{CHCHCHCH}$ ), 2.7-2.6 (t, 4H, $\left.\mathrm{COCH}_{2} \mathrm{CH}_{2} \mathrm{CO}\right) .{ }^{13} \mathrm{C} \mathrm{NMR}\left(75.5 \mathrm{MHz}, \mathrm{CDCl}_{3} / \mathrm{TFA}\right)$,

$172 \delta(\mathrm{ppm}): 176.7$ (CO), 93.2, 88.3, 76.2, 74.5, 71.5, 68.4, 67.0, 61.8, 20.9.

173 Hydrolytic degradation and biodegradation

Films for hydrolytic degradation and biodegradation studies were prepared with a thickness of $\sim 200 \mu \mathrm{m}$ by casting from chloroform solution at a polymer concentration of $100 \mathrm{~g} \cdot \mathrm{L}^{-1}$. The films were cut into $10 \mathrm{~mm}$ diameter, $20-30 \mathrm{mg}$ weight disks and dried under vacuum to constant weight. For hydrolytic degradation, samples were immersed in vials containing $10 \mathrm{~mL}$ of either citric acid buffer $\mathrm{pH} 2.0$ or sodium phosphate buffer $\mathrm{pH} 7.4$ at $37^{\circ} \mathrm{C}$. The enzymatic degradation was carried out at $37^{\circ} \mathrm{C}$ in vials containing $10 \mathrm{~mL}$ of a $\mathrm{pH} 7.4$ buffered sodium phosphate solution with added lipase from porcine pancreas $(10 \mathrm{mg})$ and replacing the supernatant every $72 \mathrm{~h}$ to maintain the enzyme activity. In both cases, the disks were withdrawn from the incubation medium after scheduled periods of time, washed carefully with distilled water, dried to constant weight, and analyzed by GPC chromatography and NMR spectroscopy.

\section{Results and discussion}

\section{Synthesis and chemical structure}

The monomer 2,4:3,5-di-O-methylene-D-glucitol (Glux-diol) with the required purity and in satisfactory yield was prepared from commercially available 1,5-Dgluconolactone as it has been previously reported by us. ${ }^{22}$ Polycondensation in the melt was the method chosen to prepare both homopolyesters and copolyesters in agreement with that is usual in the industrial practice, and the applied procedure conditions were as close as possible to those reported for the synthesis of Manxcontaining PBS copolyesters. ${ }^{21}$ As it is depicted in Scheme 2, the polymerization procedure consisted in two steps, first generation of hydroxyl capped oligoesters by transesterification under a nitrogen flow to prevent decomposition of Glux, and second, polycondensation under vacuum to remove the excess of BD as much as possible. 
Reaction conditions regarding time and temperature were optimized for each individual case. Both the homopolyester PGluxS and the series of copolyesters $\mathrm{PB}_{\mathrm{x}} \mathrm{Glux}_{\mathrm{y}} \mathrm{S}$ containing Glux units from 5 up to 70 mole-\% were thus synthesized.
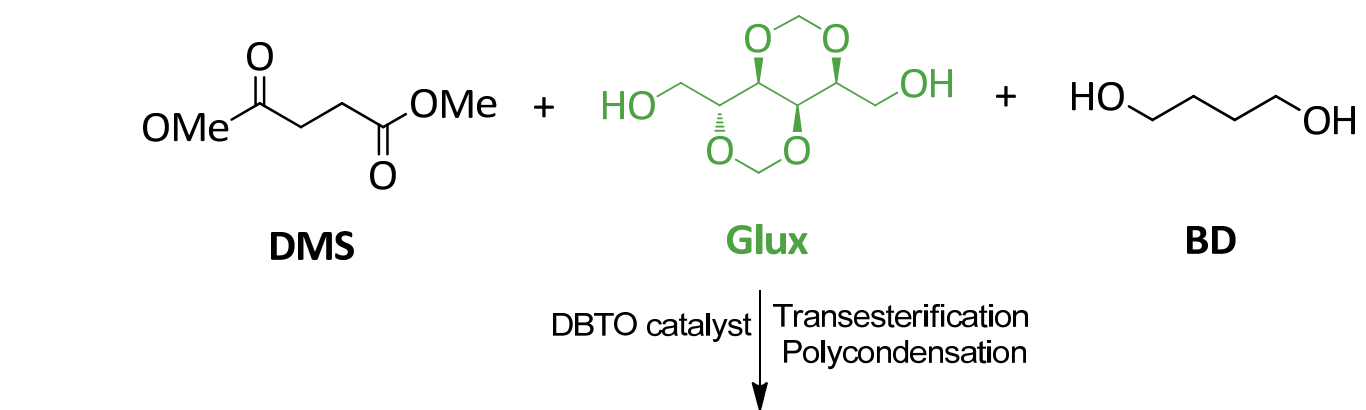

Scheme 2 Polycondensation reactions leading to $\mathrm{PB}_{\mathrm{x}} \mathrm{Glux}_{\mathrm{y}} \mathrm{S}$ copolyesters. Only asymmetric carbons keeping a unique spatial orientation along the copolyester chain ( 3 and 4 carbons of the Glux unit) have been stereochemically represented.

The chemical constitution of the polyesters was assessed by NMR. As an example, both ${ }^{1} \mathrm{H}$ and ${ }^{13} \mathrm{C}$ NMR spectra of $\mathrm{PB}_{50} \mathrm{Glux}_{50} \mathrm{~S}$ with indication of all signals assignments are shown in Fig. 1. NMR spectra of $\mathrm{PB}_{90} \mathrm{Glux}_{10} \mathrm{~S}$ and PGluxS are provided in the ESI file (Fig. SI-1 and SI-2). Data regarding composition, molecular weight and microstructure of $\mathrm{PB}_{\mathrm{x}} \mathrm{Glux} \mathrm{y}$ copolyesters and homopolyesters are collected in Table 1. Copolyester compositions were determined by integration of the proton signals arising from BD and Glux units in the by ${ }^{1} \mathrm{H}$ NMR spectra. As it is seen in Table 1 , copolyester compositions are very close to those used in their respective feeds with a slight excess in the Glux content. The GPC analysis revealed that polyesters were obtained with weight average molecular weights within the $46,000-26,000$ range with dispersity degrees oscillating between 2.2 and 3.1. The general trend is that molecular weights slightly decrease with the increasing amount of Glux units in the polymer chain 
so that the minimum value is attained for the PGluxS homopolyester. Intrinsic

225 viscosities decreased from 1.0 to near $0.4 \mathrm{dL} \cdot \mathrm{g}^{-1}$ in agreement with the trend observed 226 for molecular weights. According to which has been repeatedly noticed for other 227 polyesters containing sugar residues, ${ }^{19}$ such a trend is very likely determined by the high sensitivity to heat of 2,4:3,5-di-O-methylene-D-glucitol and the relatively high temperatures used in the polymerization reaction.

Table 1. Composition, molecular weights and microstructure of polyesters.

\begin{tabular}{|c|c|c|c|c|c|c|c|c|c|}
\hline \multirow[t]{3}{*}{ Polyester } & \multicolumn{2}{|c|}{$\begin{array}{l}\text { Composition } \\
(\mathrm{mol} / \mathrm{mol})\end{array}$} & \multicolumn{4}{|c|}{ Molecular weight } & \multicolumn{3}{|c|}{ Microstructure } \\
\hline & \multicolumn{2}{|c|}{ Feed Copolyester ${ }^{a}$} & $\begin{array}{c}{[\eta]^{D}} \\
\left(\mathrm{dL} \cdot \mathrm{g}^{-1}\right) \\
\end{array}$ & $M_{\mathrm{n}}{ }^{c}$ & $M_{\mathrm{w}}{ }^{\mathrm{c}}$ & $D^{c}$ & \multicolumn{2}{|c|}{$\begin{array}{c}\text { Average } \\
\text { sequence length }\end{array}$} & \multirow[t]{2}{*}{$R^{d}$} \\
\hline & \multicolumn{2}{|c|}{$X_{\mathrm{BD}} / X_{\mathrm{Glux}}$} & & & & & $n_{\mathrm{B}}$ & $n_{\mathrm{G}}$ & \\
\hline PBS & $100 / 0$ & $100 / 0$ & 1.00 & 17900 & 45600 & 2.5 & - & - & - \\
\hline $\mathrm{PB}_{95} \mathrm{Glux}_{5} \mathrm{~S}$ & $95 / 5$ & $94.4 / 5.6$ & 0.71 & 17000 & 43700 & 2.6 & 9.9 & 1 & 1.10 \\
\hline $\mathrm{PB}_{90} \mathrm{Glux}_{10} \mathrm{~S}$ & $90 / 10$ & $88.9 / 11.1$ & 0.65 & 14900 & 43400 & 2.9 & 6.3 & 1.2 & 0.96 \\
\hline $\mathrm{PB}_{70} \mathrm{Glux}_{30} \mathrm{~S}$ & $70 / 30$ & $71.2 / 28.8$ & 0.60 & 14000 & 39300 & 2.8 & 2.6 & 1.7 & 0.98 \\
\hline $\mathrm{PB}_{50} \mathrm{Glux}_{50} \mathrm{~S}$ & $50 / 50$ & $46.2 / 53.8$ & 0.59 & 12900 & 36700 & 2.8 & 1.6 & 2.6 & 1.00 \\
\hline $\mathrm{PB}_{30} \mathrm{Glux}_{70} \mathrm{~S}$ & $30 / 70$ & $25.4 / 74.6$ & 0.60 & 12600 & 38500 & 3.1 & 1.3 & 4.8 & 0.98 \\
\hline PGluxS & $0 / 100$ & 0/100 & 0.41 & 12300 & 26800 & 2.2 & - & - & - \\
\hline
\end{tabular}

${ }^{\mathrm{a}}$ Molar composition determined by integration of ${ }^{1} \mathrm{H}$ NMR spectra.

${ }^{\mathrm{b}}$ Intrinsic viscosity measured in dichloroacetic acid at $25^{\circ} \mathrm{C}$.

${ }^{\circ}$ Determined by GPC in HFIP against PMMA standards.

${ }^{\mathrm{d}}$ Randomness degree of copolyesters calculated on the basis of the ${ }^{13} \mathrm{C}$ NMR analysis.

The microstructure of the copolyesters was determined by ${ }^{13} \mathrm{C} N M R$ taking benefit from the sensitiveness of the carbonyl groups to the sequence distribution at the dyads level (BB, BG, GB, GG). As a consequence of the occurrence of different dyads and also of the two orientations for the Glux unit, the $\mathrm{CO}$ signal splits into multiple peaks that appear spread within the $176.8-175.3 \mathrm{ppm}$ interval (Fig. 2). Nevertheless, three groups of peaks may be discerned in such spectra which are arising from the four types of diol-dyads present in the copolyester chain. Although it is known that different carbons frequently have different relaxation times, it is not the case because the composition calculated using these carbon signals was the same as that obtained by ${ }^{1} \mathrm{H}$ NMR. Then, the integration of all the dyad-associated peaks and application of the equations given below, allowed estimating the number average 
242 sequence lengths to evaluate the microstructure of the copolyesters according to the 243 randomness degree $R$.
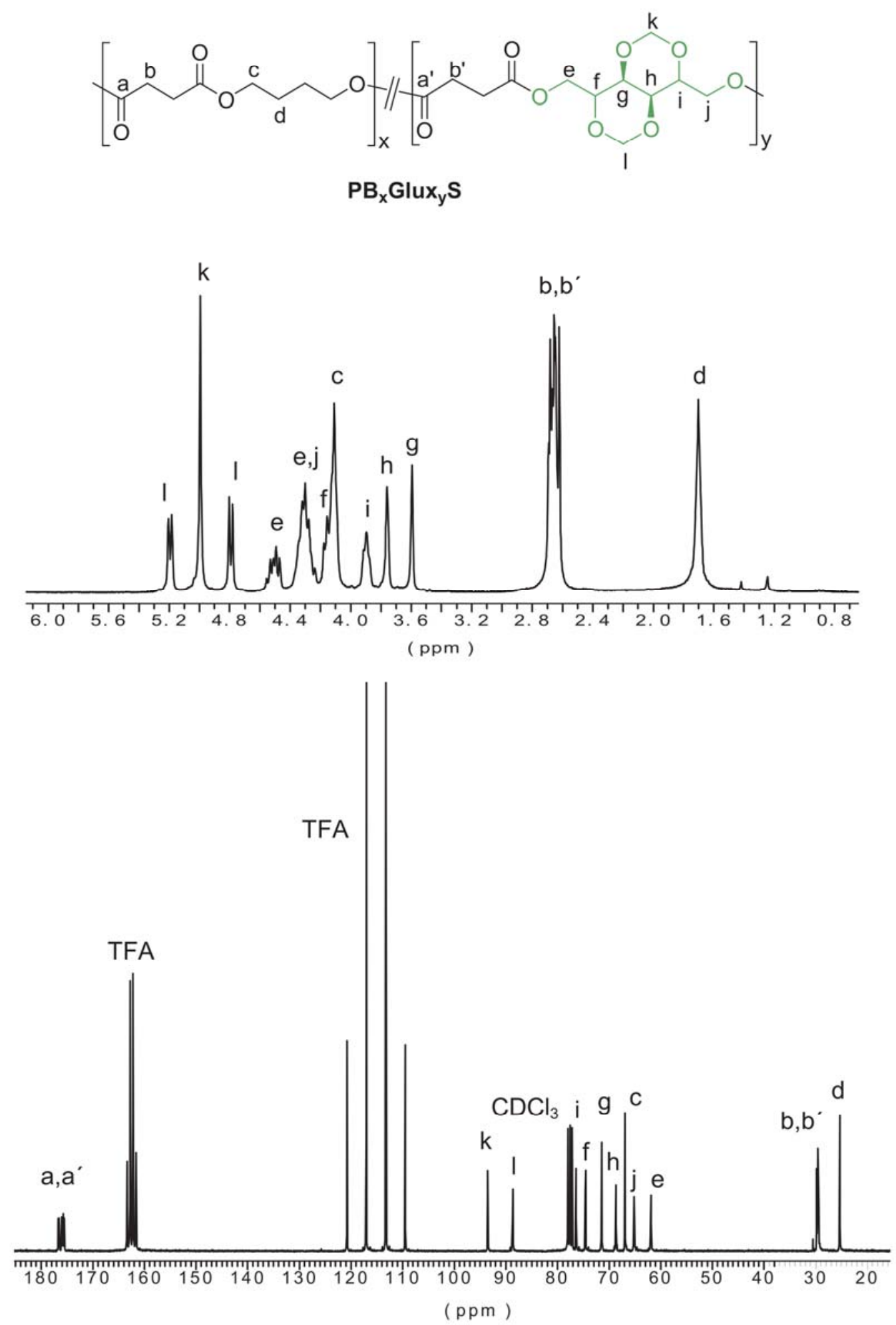
The values resulting from these calculations are given in Table 1 and they indicate that

247 an almost random microstructure is shared by all the copolyesters $(R \sim 1)$.

248

249

$$
n_{B}=(B B+0.5(B G+G B)) / 0.5(B G+G B) \quad n_{G}=(G G+0.5(G B+B G)) / 0.5(B G+G B)
$$

250

$$
R=1 / n_{B^{+}} 1 / n_{G}
$$

251

252

253

254

255

256

257

258

259

260

261

PBS

PGluxS
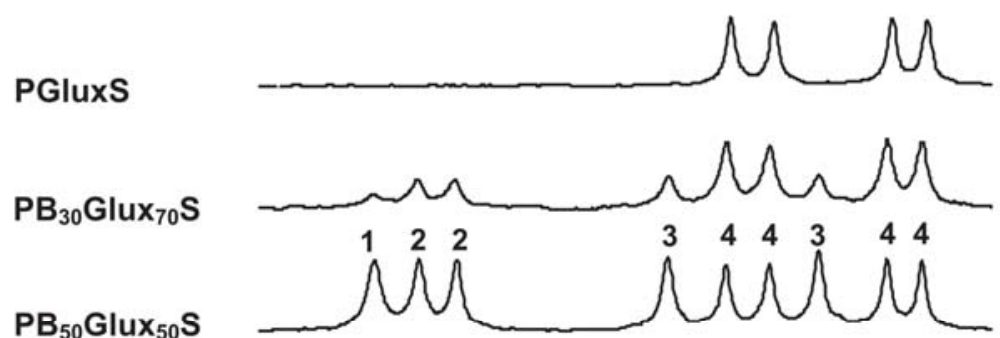

$\mathrm{PB}_{50}$ Glux $_{50} \mathrm{~S}$

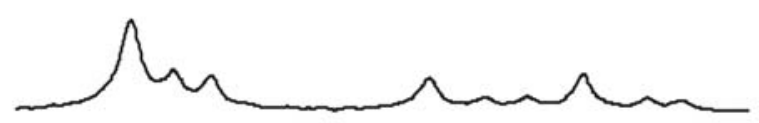

$\mathrm{PB}_{70} \mathrm{Glux}_{30} \mathrm{~S}$

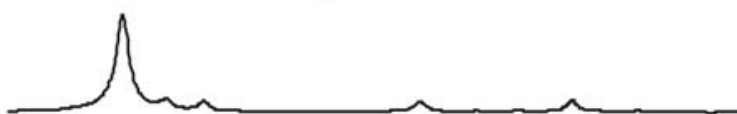

$\mathrm{PB}_{90} \mathrm{Glux}_{10} \mathrm{~S}$

$\mathrm{PB}_{95} \mathrm{Glux}_{5} \mathrm{~S}$
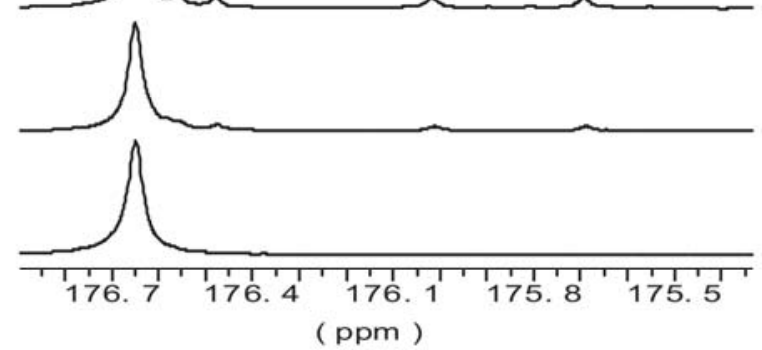

262

263<smiles>COCCCCOC(=O)CCC(=O)OCCCCOC</smiles>

BB

264

265

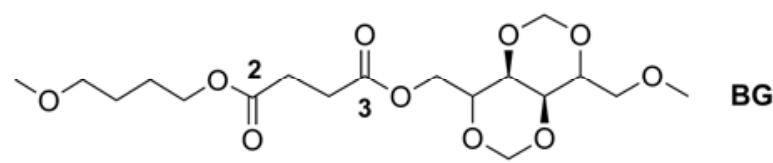

266

267<smiles>COCCCCOC(=O)CCC(=O)OCC1OCOC2C(COC)OCOC12</smiles>

GB

268

269

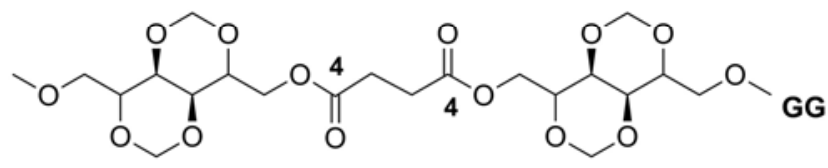

271

Fig. $2{ }^{13} \mathrm{C}$ NMR spectra showing the changes undergone by the carbonyl signal of $\mathrm{PB}_{x} \mathrm{Glux}_{y} \mathrm{~S}$ copolyesters with variations in composition. 


\section{Thermal properties and crystallization}

The basic thermal properties of the obtained copolyesters were evaluated by TGA and DSC with special attention to the influence of the presence of the Glux units on decomposition, melting and glass transition temperatures. Data afforded by these analyses are collected in Table 2.

The recorded TGA traces for the whole series are compared in Fig. 3. All traces except that of PGluxS obey the same behavior pattern consisting of one only decomposition step that starts around $340{ }^{\circ} \mathrm{C}$, fells down at the proximities of $400{ }^{\circ} \mathrm{C}$ (see Fig. SI-3) and leaves less than $10 \%(\mathrm{w} / \mathrm{w})$ of residual weight. A detailed comparison of the decomposition parameters reveals that the insertion of the Glux units in PBS does not alter significantly the thermal stability of the parent polyester provided that the case for homopolyester PGluxS is excluded. In fact, the maximum change observed for the onset temperature is a decrease in $10{ }^{\circ} \mathrm{C}$ whereas the maximum rate decomposition temperature slightly increases with copolymerization.

The fact that opposite tendencies are observed for ${ }^{\circ} T_{\mathrm{d}}$ and ${ }^{\max } T_{\mathrm{d}}$ respectively, suggests the presence of small amounts of structural water associated to the Glux units in $\mathrm{PB}_{\mathrm{x}} \mathrm{Glux}_{\mathrm{y}} \mathrm{S}$ copolyesters. The exceptional behavior observed for PGluxS can be explained by assuming that it contains adsorbed water in much larger amounts than copolyesters, a conjecture that makes much sense given the 100 mole- $\%$ content of this homopolyester in Glux units. The high heat resistance displayed by $\mathrm{PB}_{x} \mathrm{Glux}_{\mathrm{y}} \mathrm{S}$ is a really remarkable fact regarding the potential of these copolyesters to be used in applications involving thermal processing. 
Table 2. Thermal and mechanical properties and X-ray spacings of $\mathrm{PB}_{\mathrm{x}} \mathrm{Glux} \mathrm{y}$ S polyesters.

\begin{tabular}{|c|c|c|c|c|c|c|c|c|c|c|c|c|c|c|c|c|c|c|}
\hline \multirow{2}{*}{ Polyester } & \multirow{2}{*}{\multicolumn{3}{|c|}{$\mathrm{TGA}^{\mathrm{a}}$}} & \multicolumn{11}{|c|}{$\mathrm{DSC}^{\mathrm{b}}$} & \multirow{2}{*}{$\begin{array}{l}\mathrm{XRD}^{\mathrm{C}} \\
d-(\mathrm{nm})\end{array}$} & \multicolumn{3}{|c|}{ Stress-strain essays $^{d}$} \\
\hline & & & & \multicolumn{3}{|c|}{ First heating } & $\begin{array}{c}\frac{\text { Cooling }}{T_{\mathrm{c}}} \\
\left({ }^{\circ} \mathrm{C}\right)\end{array}$ & \multicolumn{3}{|c|}{ Second heating } & \multicolumn{4}{|c|}{$t_{1 / 2}(\min )\left(\right.$ at $\left.^{\circ} \mathrm{C}\right)$} & & $\begin{array}{c}E \\
(\mathrm{MPa})\end{array}$ & $\begin{array}{c}\sigma_{\max } \\
(\mathrm{MPa})\end{array}$ & $\begin{array}{c}\varepsilon \\
(\%)\end{array}$ \\
\hline $\mathrm{PB}_{95} \mathrm{Glux}_{5} \mathrm{~S}$ & 332 & 390 & 5 & -28 & 106 & 70 & 62 & 90 & 106 & 63 & 1.2 & 2.3 & - & - & $0.45,0.40,0.39$ & $482 \pm 10$ & $13 \pm 2$ & $4 \pm 1$ \\
\hline $\mathrm{PB}_{90} \mathrm{Glux}_{10} \mathrm{~S}$ & 330 & 392 & 3 & -20 & 96 & 54 & 33 & 30 & 96 & 48 & 18.7 & 28.0 & - & - & $0.45,0.40,0.39$ & $370 \pm 13$ & $16 \pm 1$ & $10 \pm 2$ \\
\hline $\mathrm{PB}_{70} \mathrm{Glux}_{30} \mathrm{~S}$ & 337 & 405 & 7 & 14 & 59 & 33 & - & - & - & & & & & & $0.46,0.40$ & $348 \pm 15$ & $11 \pm 1$ & $4 \pm 2$ \\
\hline $\mathrm{PB}_{30} \mathrm{Glux}_{70} \mathrm{~S}$ & 338 & 403 & 8 & 80 & - & - & - & - & - & & & & & & & $1356 \pm 19$ & $40 \pm 3$ & $6 \pm 2$ \\
\hline PGluxS & 264 & 403 & 9 & 103 & - & - & - & - & - & & & & & & & - & - & - \\
\hline
\end{tabular}

${ }^{a}$ Onset decomposition temperature corresponding to $5 \%$ of weight loss $\left({ }^{\circ} T_{\mathrm{d}}\right)$, temperature for maximum degradation rate $\left({ }^{\text {max }} T_{\mathrm{d}}\right)$, and $\%$ of weight remaining after heating at $600{ }^{\circ} \mathrm{C}(R W)$.

${ }^{\mathrm{b}}$ Glass-transition temperature $\left(T_{\mathrm{g}}\right)$ taken as the inflection point of the heating DSC traces of melt-quenched samples recorded at $20^{\circ} \mathrm{C} \cdot \mathrm{min}^{-1}$. Melting $\left(T_{\mathrm{m}}\right)$ and crystallization $\left(T_{\mathrm{c}}\right)$ temperatures, and melting enthalpy $\left(\Delta H_{\mathrm{m}}\right)$ measured at heating/cooling rates of $10^{\circ} \mathrm{C} \cdot \mathrm{min}^{-1}$. Isothermal crystallization half-time $\left(t_{1 / 2}\right)$ determined at the indicated temperatures.

${ }^{\mathrm{c} B r a g g}$ spacings measured by powder $\mathrm{X}$-ray diffraction.

${ }^{\mathrm{d}}$ Elastic modulus $(E)$, maximum stress $(\sigma)$ and elongation to break $(\varepsilon)$ measured by tensile testing from hot-pressing films. 
Fig. 3 TGA traces of $\mathrm{PB}_{x} \mathrm{Glux}_{y} \mathrm{~S}$.

The glass transition and melting temperatures of $\mathrm{PB}_{\mathrm{x}} \mathrm{Glux}_{\mathrm{y}} \mathrm{S}$ copolyesters and homopolyesters were measured by DSC. Observation of the slope changes were clearly seen for the whole series on traces recorded from samples quenched from the melt that were exempted of crystallinity (see Fig. SI-5). The $T_{\mathrm{g}}$ observed for copolyesters varied from -28 to $80{ }^{\circ} \mathrm{C}$ with values steadily increasing for increasing contents in Glux units (Table 2). This range of values is fully consistent with the $T_{\mathrm{g}}$ values displayed by the parent homopolyesters $\left(-37^{\circ} \mathrm{C}\right.$ and $103^{\circ} \mathrm{C}$ for PBS and PGluxS, respectively). Such strong enhancing effect is just simply the consequence of copolyesters with contents in Glux units of 30 mole- $\%$ as maximum displayed an endothermic peak characteristic of melting and revealed therefore that they are semicrystalline. Both $T_{\mathrm{m}}$ and $\Delta H_{\mathrm{m}}$ decreased as the presence of Glux units increased. 
327 homopolyester produced plain traces without any vestige of crystallinity. This tendency

328 is a consequence of the depressing effect on chain regularity that is produced when

329 butylene units are replaced by Glux units.

330 The X-ray diffraction analysis corroborated the DSC results by showing discrete scattering diffraction for PBS and $\mathrm{PB}_{\mathrm{x}} \mathrm{Glux}_{\mathrm{y}} \mathrm{S}$ copolyesters containing up to $30 \%$ of Glux units with a peak sharpness and intensity decreasing with the increasing B/Glux ratio (Fig. 4b). Moreover the reflections observed for the semicrystalline copolyesters were coincident in both spacing and intensity with those characteristic of $\mathrm{PBS}^{23}$ which is indicative that the crystal structure of the homopolyester is retained after copolymerization.

Fig. 4 DSC heating traces of the whole series of $\mathrm{PB}_{\mathrm{x}} \mathrm{Glux} \mathrm{x}$ recorded at heating at $10{ }^{\circ} \mathrm{C} \cdot \mathrm{min}^{-1}$ from samples coming from synthesis (a), X-ray diffraction profiles of the indicated $\mathrm{PB}_{\mathrm{x}} \mathrm{Glux}_{\mathrm{y}} \mathrm{S}$ copolyesters (b).

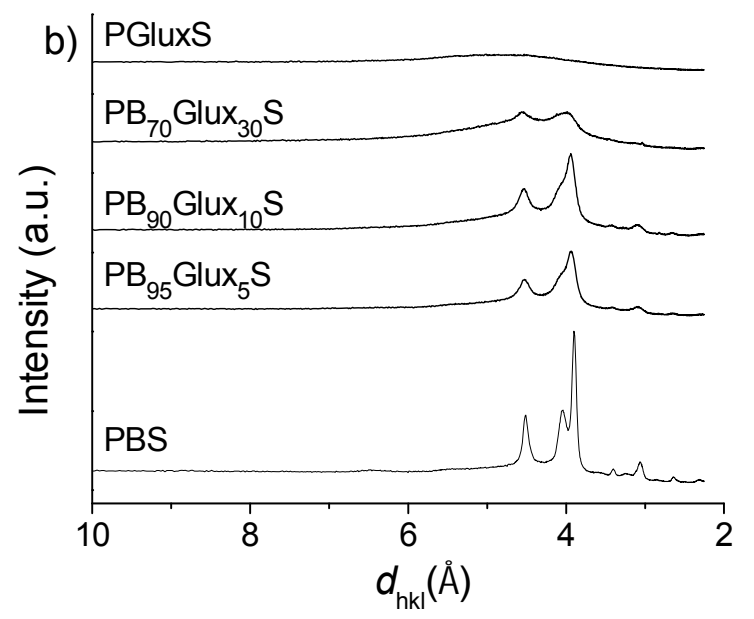


has to be considered when they are intended to be used as thermoplastics. As it can be seen in Table 2 only $\mathrm{PB}_{\mathrm{x}}$ Glux $\mathrm{S}$ copolyesters containing 10 mole- $\%$ of Glux as maximum are able to crystallize from the melt (Fig. SI-4). Although these results clearly indicated that crystallizability of PBS is strongly depressed by the insertion of Glux units in the polyester chain, and that such effect has been reported to invariably occur for other related copolyesters containing sugar units, a comparative crystallization kinetics study has been undertaken in this work to quantify the influence of Glux in this regard.

PBS, $\mathrm{PB}_{95}$ Glux $_{5} \mathrm{~S}$ and $\mathrm{PB}_{90}$ Glux $10 \mathrm{~S}$ were compared regarding their isothermal crystallization although a common temperature could not be set for the three compounds due to their large differences in crystallizability. The study also included the crystallization of each polymer at two different crystallization temperatures in order to estimate the influence of temperature on crystallization rate. The graphical representations of crystallization data as a function of time are depicted in Fig. 5 for the three compared polyesters. The kinetics was evaluated by the classical Avrami model, ${ }^{24,25}$ and the crystallization half-times afforded by this analysis are given in Table
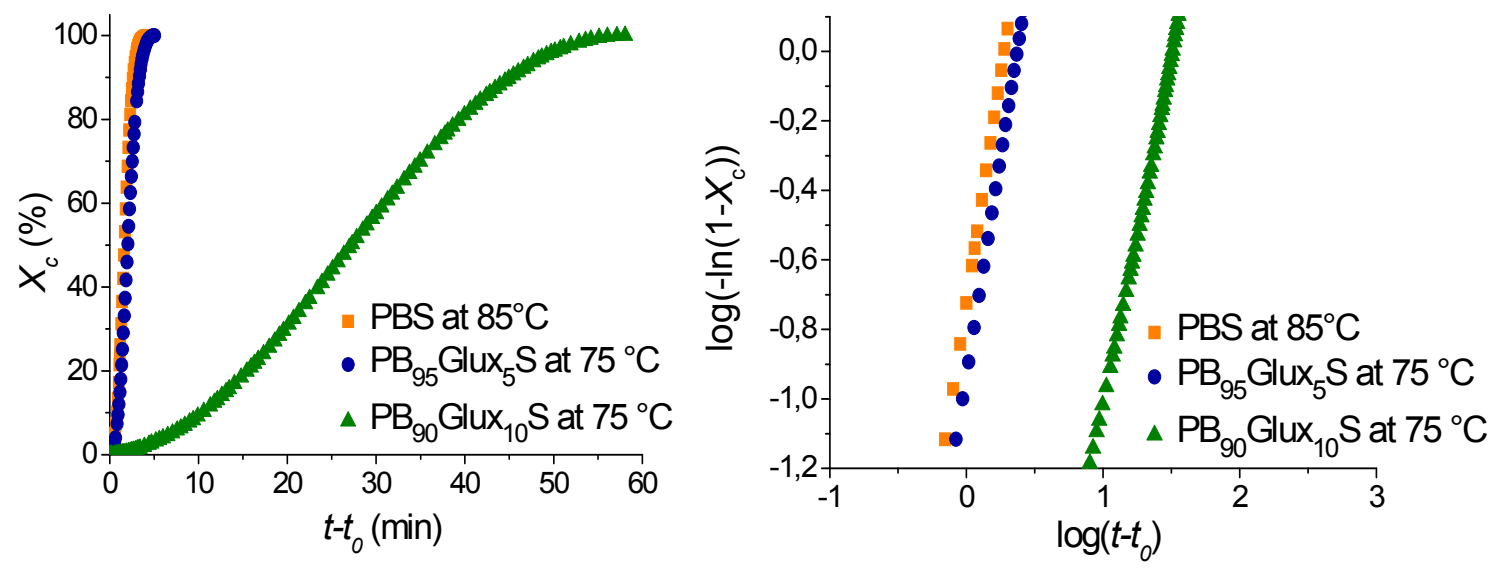

Fig. 5 Isothermal crystallization of $\mathrm{PBS}, \mathrm{PB}_{95} \mathrm{Glux}{ }_{5} \mathrm{~S}$ and $\mathrm{PB}_{90} \mathrm{Glux}_{10} \mathrm{~S}$ at the indicated temperatures. Relative crystallinity vs. crystallization time (left), Avrami representation of crystallization data (right). 
more than ten times for an increase in the Glux content of only 5 mole- $\%$. On the other hand, the observed inverse dependence of crystallization rate on temperature indicates that in both PBS and copolyesters, the crystallization process is controlled mainly by nucleating factors rather than by chain mobility. ${ }^{24}$

\section{Stress-strain behavior}

For a preliminary assessment of the mechanical behavior of $\mathrm{PB}_{\mathrm{x}} \mathrm{Glux} \mathrm{S}$, films of the copolyesters were subjected to stress-train essays testing. Considering the strong influence that crystallinity has on mechanical properties, the samples used for tensile testing were previously checked by DSC. These measurements proved that melting parameters $\left(T_{\mathrm{m}}\right.$ and $\left.\Delta H_{\mathrm{m}}\right)$ of films were close to those recorded for the powdered samples with the initial PBS crystallinity decreasing about 20,30 and $50 \%$ for 5,10 and 30 mole- $\%$ of Glux in the copolyester, respectively, to finally disappear for higher contents. The copolyesters were tested in parallel and compared with PBS. The mechanical parameters obtained in these essays are gathered in Table 2. Results showed that the copolyesters with amounts of Glux units till 30 mole-\%, which are those displaying crystallinity, undergo a reduction in Young modulus and tensile strength whereas those with higher contents of Glux exhibit a sustained increasing in these parameters. Although rather wandering values were found for the elongation to break, probably due to sample heterogeneities and divergences in molecular weight, it can be reasonably concluded that ductility is not significantly modified by copolymerization. The ambiguous mechanical behavior exhibited by $\mathrm{PB}_{x} \mathrm{Glux}_{y} \mathrm{~S}$ copolyesters reflects the ambivalent effect of the insertion of Glux unit in the PBS chain as far as crystallinity and chain mobility in the amorphous phase is concerning. For low contents in Glux, crystallinity is the main factor determining the stress-strain response, and $E$ and $\sigma_{\max }$ decrease with copolymerization. Conversely, for high Glux contents crystallinity disappears and $T_{\mathrm{g}}$ becomes the only property affecting deformation. Consequently the mechanical performance is improved with copolymerization to the 
418 point that amorphous $\mathrm{PB}_{\mathrm{x}} \mathrm{Glux} \mathrm{S}$ copolyesters arrive to be stiffer and stronger than 419 PBS.

\section{Hydrolytic degradation and biodegradation}

In order to evaluate the effect of Glux on the behavior of PBS regarding its degradability and biodegradability, several essays were carried out in parallel using PBS, PGluxS and $\mathrm{PB}_{70}$ Glux $_{30} \mathrm{~S}$ copolyester. Samples were incubated in the appropriate aqueous buffer solution, with or without lipases added, and degradation evolution was followed by monitoring the changes taking place in weight and molecular weight of the residue. Firstly, the degradation at $\mathrm{pH} 2.0$ was performed to evaluate the influence of Glux on the chemical hydrolysis of PBS and results coming out from these essays have been plotted in Fig. 6 ( $a$ and a'). According to what should be expected for aliphatic polyesters, a continuous decreasing in both sample weight and polymer molecular weight is observed for the three polyesters along incubation time with the noticeable remark that changes became more accentuated for Glux containing polyesters. In second place the degradation of the three polyesters incubated under approximately physiological conditions both with and without porcine pancreas lipases added, was examined, and results obtained therein are presented also in Fig. 6 ( $b$ and b'). As expected, degradation at $\mathrm{pH} 7.4$ took place in much less extent than at $\mathrm{pH} 2.0$ but the changes observed in both $W$ and $M_{n}$ continued being of the same sign as before for the three tested polyesters. Interestingly, degradation was notably enhanced when lipases were added to the incubation medium to the point that changes taking place in $W$ and $M_{\mathrm{n}}$ were comparable to those observed at $\mathrm{pH} 2.0$. To get insight into the hydrolytic mechanism, the residue left by the $\mathrm{PB}_{70} \mathrm{Glux}_{30} \mathrm{~S}$ after incubation at $\mathrm{pH} 2.0$ for 40 days was analyzed by ${ }^{1} \mathrm{H}$ NMR, which revealed that the content in Glux of this sample had decreased about $10 \%$, i.e. about one third of the Glux units were released upon degradation. This result is demonstrative that hydrolysis of PBS containing Glux units mostly happens by breaking those ester groups in which the carbohydrate units are 
445 directly implied. Such a difference is also observed when the homopolyesters PGluxS

446 and PManxS are compared (see Fig. SI-6). All these results lead to conclude that not

447 only the chemical degradation but also the biodegradability of PBS, becomes

448 enhanced by the insertion of Glux units in the polyester chain.

449

450

451

452

453

454
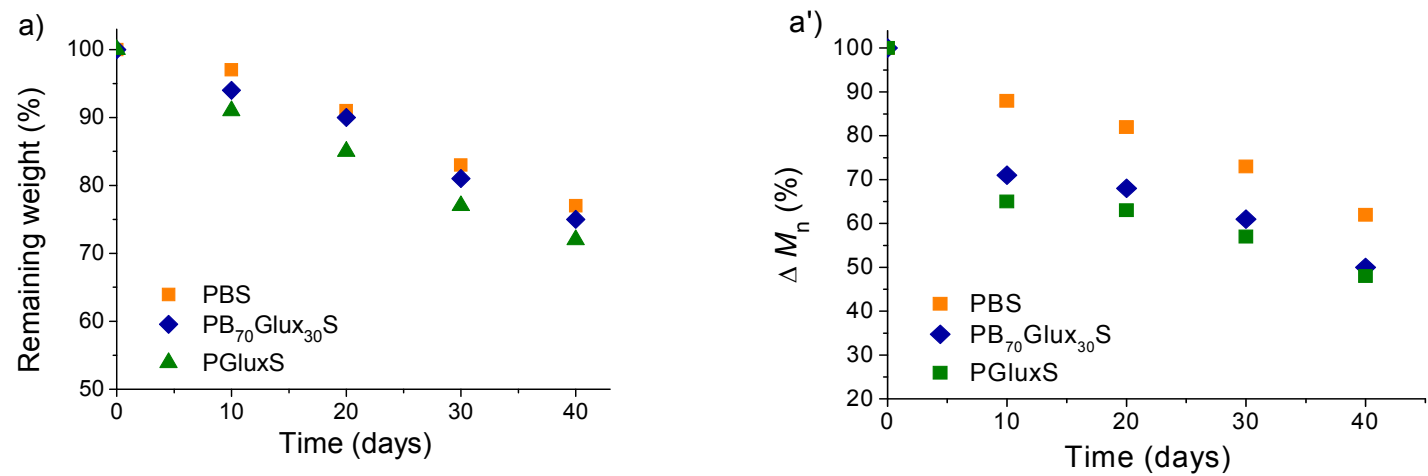

455

456

b)

457

458

459

460

461

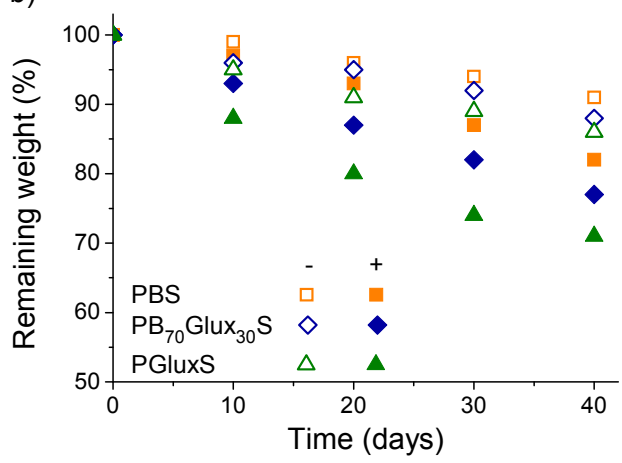

b')

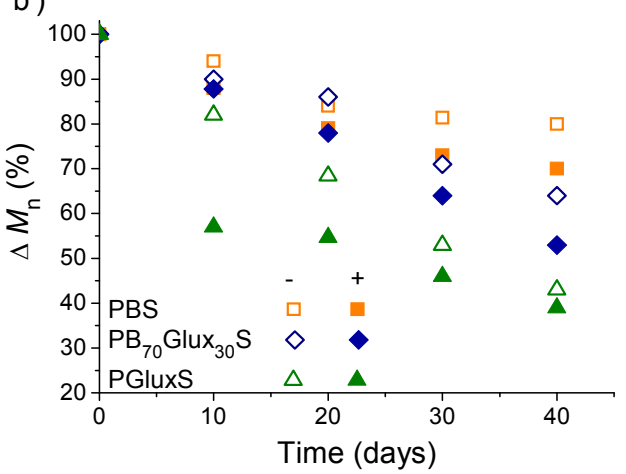

462

Fig. 6 Degradation plots of PBS, $\mathrm{PB}_{70} \mathrm{Glux}_{30} \mathrm{~S}, \mathrm{PGluxS}$ at pH $2.0\left(\mathrm{a}, \mathrm{a}^{\prime}\right)$ and $\mathrm{pH} 7.4$ with and without porcine pancreas enzyme added $\left(b, b^{\prime}\right)$.

464

465

466

467

\section{Sugar-based bicyclic diols compared}

468

The results achieved in this work have proven the ability of Glux-diol (2,4:3,5-di-

O-methylene-D-glucitol) to be used as monomer for the preparation of PBS results but using Manx-diol (2,4:3,5-di-O-methylene-D-mannitol) has been recently

472 published by us. ${ }^{21}$ It is of interest comparing these two bicyclic diols as comonomers of 473 1,4-butanediol for the preparation of PBS copolyesters. 
procedure have a random microstructure, their compositions are in general close to those used in their respective polymerization feeds, and their divergences regarding molecular weights are less than $15 \%$ (Fig. SI-7). The two hydroxymethyl groups of Manx-diol are indistinguishable and equatorially oriented whereas in the asymmetrical

479 Glux-diol, one $\mathrm{CH}_{2} \mathrm{OH}$ group is equatorial and the other one is axial. A recent study on 480 the use of Glux-diol as comonomer in the solid state modification of PBT has shown that the reactivity of the axially oriented hydroxyl function in transesterification reactions was significantly hindered. ${ }^{26}$ However the slight differences in synthesis results attained for the two PBS copolyester series indicate that such hindering effect must not be significant in this case.

Although neither $\mathrm{PB}_{\mathrm{x}} \mathrm{Glux}_{\mathrm{y}} \mathrm{S}$ nor $\mathrm{PB}_{\mathrm{x}} \mathrm{Manx}_{\mathrm{y}} \mathrm{S}$ copolyesters should be expected to be stereoregular due to the random distribution of the comonomers along their respective chains, the disorder will be less severe in the later due to the twofold symmetry of the Manx configuration. Accordingly $\mathrm{PB}_{x} \mathrm{Manx}_{y} \mathrm{~S}$ copolyesters show a greater ability to crystallize; they are crystalline over the whole range of compositions with crystallinity degrees oscillating between 50 and 65 mole-\%. As it is shown in Fig. $7 \mathrm{a}, T_{\mathrm{m}}$ values in this series display a parabolic tendency with the minimum placed at comonomer compositions no far from 30 mole- $\%$ and the maximum at 100 mole- $\%$ (homopolyester PManxS). In contrast, only $\mathrm{PB}_{\mathrm{x}} \mathrm{Glux}_{\mathrm{y}} \mathrm{S}$ copolyesters containing 30 mole-\% of Glux units as maximum were found to be crystalline. Furthermore no sign of crystallinity was detected for PGluxS. Nevertheless practically identical $T_{\mathrm{m}}$ values are displayed by the two series over the interval in which $\mathrm{PB}_{\mathrm{x}} \mathrm{Glux} \mathrm{y} S$ are able to crystallize. bicyclic sugar-based compounds as comonomers in the synthesis of aliphatic polyesters. A close comparison of the $T_{g}$ values displayed by $\mathrm{PB}_{\mathrm{x}} \mathrm{Glux}_{\mathrm{y}} \mathrm{S}$ and $\mathrm{PB}_{\mathrm{x}} \mathrm{Manx} \mathrm{x}_{\mathrm{y}} \mathrm{S}$ series is graphically afforded in Fig. $8 \mathrm{~b}$. An almost linear trend is followed in both cases with slopes of $\sim 1.5$ and $\sim 1.0^{\circ} \mathrm{C} \cdot$ mole- $^{2} \cdot$ sugar unit $^{-1}$, respectively. The 
502 fact that higher $T_{\mathrm{g}}$ 's are displayed by copolyesters containing Glux units is really

503 amazing since they are less crystalline than their isocompositional Manx analogs.

504 Apparently it is the more corrugated shape of the Glux structure which additionally 505 contributes to hindering the mobility of the polyester chain and gives rise to an 506 exceptionally increase in $T_{\mathrm{g}}$. diol that has achieved in these last years wide recognition for the synthesis of biobased semicrystalline copolyesters with high $T_{\mathrm{g}}{ }^{16,28}$ It will be worth therefore to

a)

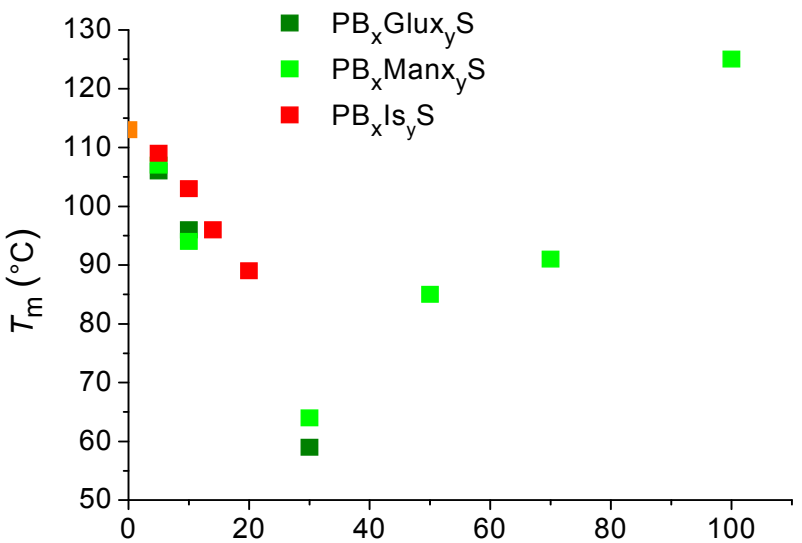

b)

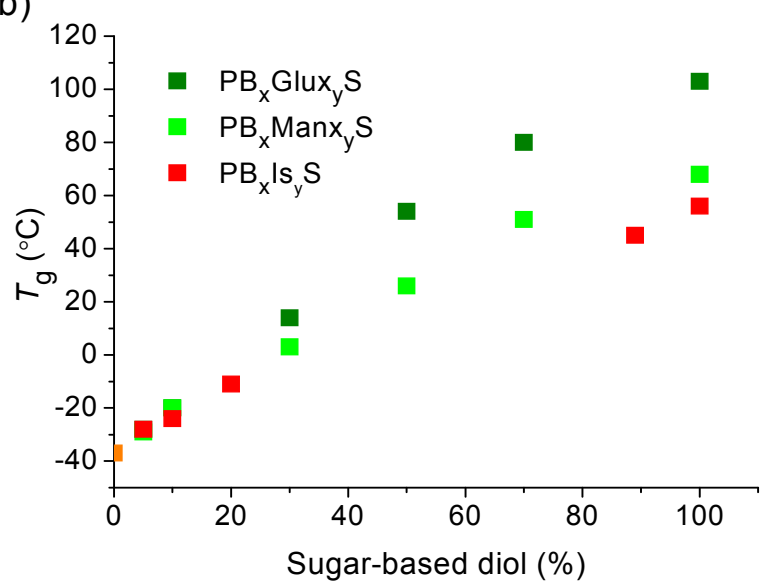

Fig. 7 Compared melting (a) and glass transition (b) temperatures of PBS copolyesters made from Glux-diol, Manx-diol and isosorbide (Jacquel et al., 2015; Tan et al., 2011). PBS data in orange.

Isosorbide (Is, 1,3:4,6-dianhydride-D-glucitol) is another glucose-derived bicyclic compare Is with Glux and Manx regarding thermal properties. Unfortunately only a few 
papers dealing with PBS copolyesters containing isosorbide are found in the accessible literature, ${ }^{29-31}$ and data there afforded are incomplete or not fully suitable for a reliable comparison. Noordover et al. ${ }^{16 \mathrm{~b}}$ reported low molecular weight PIsS with $T_{\mathrm{g}}$ between $\sim 50$ and $\sim 70{ }^{\circ} \mathrm{C}$ and Tan et al. ${ }^{29}$ described the a $\mathrm{PB}_{11} \mid \mathrm{S}_{89} \mathrm{~S}$ copolyester with $M_{\mathrm{n}} 14,000$ and $T_{\mathrm{g}}$ of $\sim 45{ }^{\circ} \mathrm{C}$. More recently, Jacquel et al. ${ }^{30}$ succeeded in preparing $\mathrm{PB}_{\mathrm{x}} I \mathrm{~s}_{\mathrm{y}} \mathrm{S}$ copolyesters with astonishingly high molecular weights $\left(45,000<M_{n}<55,000\right)$ although with compositions restricted to low contents in Is (less than 15 mole-\%). These copolyesters were reported to be semicrystalline with $T_{\mathrm{m}}$ decreasing with composition from $130^{\circ} \mathrm{C}$ down to $89^{\circ} \mathrm{C}$ and $T_{\mathrm{g}}$ increasing from $-28^{\circ} \mathrm{C}$ up to $-11^{\circ} \mathrm{C}$. The $T_{\mathrm{m}}$ and $T_{\mathrm{g}}$ data available on $\mathrm{PB}_{\mathrm{x}} \mathrm{I} \mathrm{s}_{\mathrm{y}} \mathrm{S}$ copolyesters have been also plotted in Fig. 8 for comparison with those of Glux and Manx. In spite of being scarce, data are enough to conclude that the effect of Is on PBS thermal properties is in line with that exerted by Manx and Glux. Copolymerization of PBS with bicyclic sugar-based monomers has proven to be not only non-detrimental for its basic properties but favoring both chemical hydrolysis and biodegradation. ${ }^{21,27}$ The presence of the sugar moiety in the polyester chain does not deactivate the enzyme function but enhances its action due to increasing chain hydrophilicity. Both Manx and Glux have an enhancing effect on degradability upon aqueous incubation, either in absence or presence of lipases, but apparently Glux is significantly more efficient than Manx (see comparison in Fig. SI-8). The higher enhancing effect displayed by Glux is most likely due to the strong depressing effect that this unit has on PBS crystallinity.

\section{Conclusions}

A series of PBS copolyesters $\left(\mathrm{PB}_{\mathrm{x}} \mathrm{Glux} \mathrm{y} S\right)$ containing bicyclic acetalized units derived from D-glucose (Glux) in addition to the homopolyester PGluxS were synthesized by melt polycondensation from mixtures of 1,4-butanediol, Glux-diol and dimethyl succinate. A complete incorporation of Glux-diol as well as satisfactory molecular weights were in general attained by careful selection of the reaction 
conditions. As it is usually observed for other sugar-based copolyesters, $\mathrm{PB}_{\mathrm{x}} \mathrm{Glux}_{\mathrm{y}} \mathrm{S}$ had a random microstructure. The presence of Glux in the polyester chain significantly modified the properties of PBS. Melting temperature and crystallinity were severely depressed so copolyesters containing more than 30 mole-\% of Glux including the homopolyester were amorphous. Oppositely, the glass transition temperature of PBS dramatically increased with the content in Glux units with a slope not paragoned by any other sugar-based described up to date. Mechanical properties of the $\mathrm{PB}_{x} \mathrm{Glux}_{\mathrm{y}} \mathrm{S}$ largely varying with composition with good results obtained for copolyesters with high contents in Glux. In line with the effect observed for other sugar-based copolyesters, $\mathrm{PB}_{\mathrm{x}} \mathrm{Glux}_{\mathrm{y}} \mathrm{S}$ display higher sensitivity to both hydrolytic degradation and biodegradation than PBS. All these results lead to finally conclude that Glux-diol is a highly appropriate bio-based comonomer to notably improve the properties of PBS as far as $T_{\mathrm{g}}$ and degradability are concerned. The exceptionally good accessibility of D-glucose as feedstock for Glux-diol is an additional merit of this compound if the modified PBS was intended to be used for industrial purposes.

\section{Acknowledgements}

This work received financial support from MINECO of Spain with Grant MAT2012-38044-C03-03 and from AGAUR with grant 2009SGR1469. Thanks also to MECD of Spain for the Ph.D. grant awarded to Elena Zakharova.

\section{Electronic Supplementary Information}

Fig. SI-1 ${ }^{1} \mathrm{H}$ NMR (top), ${ }^{13} \mathrm{C}$ (bottom) spectra of $\mathrm{PB}_{90} \mathrm{Glux}_{10} \mathrm{~S}$ copolyester with indication of peak assignments. Fig. SI-2 ${ }^{1} \mathrm{H}$ NMR (top), ${ }^{13} \mathrm{C}$ (bottom) spectra of PGluxS homopolyester with indication of peak assignments. Fig. SI-3 Derivative curves of PBS, $\mathrm{PB}_{90} \mathrm{Glux}_{10} \mathrm{~S}$ and $\mathrm{PB}_{50} \mathrm{Glux}_{50} \mathrm{~S}$. Fig. SI-4 DSC traces for $\mathrm{PB}_{95} \mathrm{Glux}_{5} \mathrm{~S}$. Fig. SI-5 Heating DSC traces of samples quenched from the melt for $T_{\mathrm{g}}$ observation. Fig. SI-6 Degradation curves representing the decay in molecular weight against incubation time for PGluxS, PManxS at pH 7.4. Fig. SI-7 Compared weight-average molecular weight of PBS copolyesters made from Glux-diol and Manx-diol. Fig. SI-8 Degradation curves representing the decay in molecular weight against incubation time for isocompositional PBS copolyesters containing Glux and Manx units at pH 7.4. 


\section{References}

1 A. Gandini, Green Chem., 2011, 13, 1061-1083.

2 R. T. Mathers, J. Polym. Sci., Part A: Polym. Chem., 2012, 50, 1-15.

3 E. S. Beach, C. Zheng and P. T. Anastas, Energy Environ. Sci., 2009, 2, 1038-1049.

4 G.-Q. Chen and M. K. Patel, Chem. Rev., 2012,112, 2082-2099.

5 A.-L. Marshall and P. J. Alaimo, Chem. Eur. J., 2010, 16, 4970-4980.

6 K. Yao and C. Tang, Macromolecules, 2013, 46, 1689-1712.

7 A. Bhatia, R. Gupta, S. Bhattacharya and H. Choi, Korea-Aust. Rheol. J., 2007, 19, 125-131.

8 X. Kong, H. Qi and J. M. Curtis, J. Appl. Polym. Sci., 2014, 131, 40579.

9 (a) J. Li, X. Luo and X. Lin, Mater. Des., 2013, 46, 902-909; (b) J. Li, X. Luo, X. Lin and Y. Zhou, Starch-Stärke, 2013, 65, 831-839.

10 J. Xu and B.-H. Guo, Biotechnol. J., 2010, 5, 1149-1163.

11 M. Snowdon, A. K. Mohanty and M. Misra, Macromol. Mater. Eng., 2015, 300, 118126.

12 J. Yang, Q. Hao, X. Liu, C. Ba and A. Cao, Biomacromolecules, 2004, 5, 209-218.

13 (a) F. Bachmann, J. Reimer, M. Ruppenstein and J. Thiem, Macromol. Rapid Commun., 1998, 19, 21-26; (b) F. Bachmann, J. Reimer, M. Ruppenstein and J. Thiem, Macromol. Chem. Phys., 2001, 202, 3410-3419.

14 M. Bueno, J. A. Galbis, M. G. García-Martín, M. V. Paz, F. Zamora and S. MuñozGuerra, J. Polym. Sci., Part A: Polym. Chem., 1995, 33, 299-305.

15 R. Quintana, A. Martínez de llarduya, A. Alla and S. Muñoz-Guerra, High Perform. Polym., 2012, 24, 24-30.

16 (a) B. A. J. Noordover, A. Heise, P. Malanowksi, D. Senatore, M. Mak, L. Molhoek, R. Duchateau, C. E. Koning and R. A. T. M. Benthem, Prog. Org. Coat., 2009, 65, 187196; (b) B. A. J. Noordover, V. G. Staalduinen, R. Duchateau, C. E. Koning, R. A. T. M. Benthem, M. Mak, A. Heise, A. E. Frissen and J. Haveren, Biomacromolecules, 2006, 7, 3406-3416.

17 (a) C. Lavilla, A. Alla, A. Martínez de Ilarduya, E. Benito, M. G. García-Martín, J. A. Galbis and S. Muñoz-Guerra, Polymer, 2012, 53, 3432-3445; (b) C. Lavilla and S. Muñoz-Guerra, Green Chem, 2013, 15, 144-151.

18 S. Muñoz-Guerra, C. Lavilla, C. Japu and A. Martínez de Ilarduya, Green Chem., 2014, 16, 1716-1739.

19 (a) C. Japu, A. Alla, A. Martínez de llarduya, M. G. García-Martín, E. Benito, J. A. Galbis and S. Muñoz-Guerra, Polym. Chem., 2012, 3, 2092-2101; (b) C. Japu, A. 
Martínez de llarduya, A. Alla, M. G. García-Martín, J. A. Galbis and S. Muñoz-Guerra, Polym. Chem., 2014, 5, 3190-3202.

20 (a) C. Lavilla, A. Martínez de llarduya, A. Alla, M. G. García-Martín, J. A. Galbis and S. Muñoz-Guerra, Macromolecules, 2012, 45, 8257-8266; (b) C. Lavilla, A. Martínez de llarduya, A. Alla and S. Muñoz-Guerra, Polym. Chem., 2013, 4, 282-289.

21 C. Lavilla, A. Alla, A. Martínez de llarduya and S. Muñoz-Guerra, Biomacromolecules, 2013, 14, 781-793.

22 R. Marín and S. Muñoz-Guerra, J. Appl. Polym. Sci., 2009, 114, 3723-3736.

23 K. J. Ihn, E. S. Yoo and S. S. Im, Macromolecules, 1995, 28, 2460-2464.

24 G. Bodor, Structural investigation of polymers, Ellis Hordwood, Toronto, 1991, ch. 6 , pp. 201-227.

25 J. A. Martins, Wd. Zhang and A. M. Brito, Rev Sci Instrum, 2005, 76, 105105.

26 E. Gubbels, C. Lavilla, A. Martínez de llarduya, B. A. J. Noordover, C. E. Koning and S. Muñoz-Guerra, J. Polym. Sci, Part A: Polym. Chem., 2014, 52, 164-177.

27 E. Zakharova, C. Lavilla, A. Alla, A. Martínez de llarduya and S. Muñoz-Guerra, Eur. Polym. J., 2014, 61, 263-273.

28 R. Sablong, R. Duchateau, C. E. Koning, G. Wit, D. Es, R. Koelewijn and J. Haveren, Biomacromolecules, 2008, 9, 3090-3097.

29 L. Tan, Y. Chen, W. Zhou, J. Wei and S. Ye, J. Appl. Polym. Sci., 2011, 121, 22912300 .

30 N. Jacquel, R. Saint-Loup, J.-P. Pascault, A. Rousseau and F. Fenouillot, Polymer, 2015, 59, 234-242. 